\title{
APLICACIÓN DE LA TELEDETECCIÓN Y LOS SISTEMAS DE INFORMACIÓN GEOGRÁFICA EN LA INTERPRETACIÓN DE ZONAS INUNDABLES. CASO DE ESTUDIO: RÍO SOAPAGA, SECTOR PAZ DE RÍO, BOYACÁ.
}

\section{APPLICATION OF REMOTE SENSING AND GIS IN THE INTERPRETATION FLOODPLAIN. CASE STUDY: SOAPAGA RIVER, PAZ DE RÍO SECTOR, BOYACÁ.}

\author{
Jhon Fredy Ardila León \\ Ingeniero Topográfico, Universidad Distrital "Francisco José de Caldas", \\ Ingeniero Contratista Instituto Geográfico Agustín Codazzi, Bogotá, Colombia. \\ johnar28@gmail.com \\ Oscar Yesid Quintero Delgado \\ Ingeniero Catastral y Geodesta, Universidad Distrital "Francisco José de Caldas", \\ Ingeniero Contratista Instituto Geográfico Agustín Codazzi, Bogotá, Colombia.
}

oskr.kintero@gmail.com

Fecha de recepción: 2 de febrero de 2013.

Fecha de aprobación: 4 de diciembre de 2013.

\section{RESUMEN}

El presente estudio busca a partir de las técnicas de teledetección y los Sistemas de Información Geográfica delimitar el área de inundación ocurrida por el desbordamiento del Río Soapaga (sector Paz de Río, Boyacá); la inundación se presenta debido a dos factores fundamentales: La fuerte temporada de lluvias ocurrida durante el primer semestre del año 2012 y agentes geológicos que generaron inestabilidad en el terreno, causando daños a viviendas, redes de acueducto y alcantarillado, vías, puentes, etc., localizados en área urbana del municipio.

El área de inundación se determina a partir de información vector (Curvas de nivel) obtenida del Modelo Digital de Elevación (MDE), asumiendo que el nivel de la inundación no excedió los 2 metros de altura con respecto al nivel medio del Río Soapaga y tomando como punto de referencia la cota 2210 . Adicionalmente, se realiza un geoprocesamiento entre la capa predial urbana del municipio y el área delimitada, para estimar el número de predios y las áreas afectadas por la inundación. 
Palabras clave: Área de inundación, modelo digital de elevación, geoprocesamiento.

\begin{abstract}
This study seeks from remote sensing techniques and GIS delineate the floodplain by the overflow occurred Soapaga river (Paz de Río sector, Boyacá); flooding occurs due to two factors: the strong rainy season occurred during the first half of 2012 and generated instability geological agents on the ground, causing damage to homes, water and sewer networks, roads, bridges, etc., located in urban area.

The flooded area is determined from vector data (contours) obtained from the digital elevation model (DEM), assuming that the level of the flood did not exceed two meters in height from the middle of the Soapaga river and taking benchmark the dimension 2210. Additionally, it takes a geoprocessing layer between the municipality's urban farm and the area enclosed, to estimate the number of farms and areas affected by the flood.
\end{abstract}

Keywords: Floodplain, digital elevation model, geoprocessing.

\section{INTRODUCCIÓN}

Las inundaciones son fenómenos naturales que ocurren cuando las aguas de los Ríos, Quebradas, Riachuelos, salen del lecho del escurrimiento debido a la falta de capacidad de transporte de uno de estos sistemas y pasa a ocupar el espacio que la población utiliza para vivienda, transporte, comercio, industria entre otros [1].

Existen a nivel internacional un sinnúmero de estudios que abordan esta problemática como eje central de investigación, siendo las entidades gubernamentales generalmente, las llamadas a realizar este tipo de estudios y en otros casos, las universidades en asocio con dichas entidades; así mismo, a nivel académico existen gran cantidad de publicaciones tanto a nivel de tesis, mono- grafías o simplemente artículos que exponen y estudian estos casos específicos [2], [3], [4], [5], [6].

En latinoamericana se han venido desarrollando este tipo de estudios en áreas con alto grado de susceptibilidad a este tipo de riesgo entre los cuales caben destacar: "Análisis de riesgo por inundaciones y deslizamientos de tierra en la microcuenca del arenal de Montserrat" [7], "Teledetección aplicada a la reducción del riesgo por inundaciones" [8], "Aplicación de sistemas de información geográfica para el modelamiento de zonas con riesgo de inundación. Caso estudio Río Lurin" [9], y "Sistema de información geográfica para la gestión de riesgo por deslizamiento de tierras e inundación del eje Araira - El Salmerón del municipio Zamora del estado Miranda" [10]. 
Para el caso colombiano, los estudios de gran envergadura se han realizado a través de las entidades estatales como el IDEAM, antiguo INGEOMINAS, IGAC, DANE, y FO$P A E$, enmarcados en algunos de los proyectos como lo son:

- Geomorfología y susceptibilidad a la inundación del valle fluvial del Magdalena, en el cual con un mayor nivel de resolución evalúa la susceptibilidad de inundación de zonas aledañas al Río Magdalena a través de un análisis de la geomorfología de la zona, de la dinámica fluvial del valle del Río Magdalena y de imágenes satelitales.

- Programa de investigación y zonificación geotécnica regional y urbana la zonificación geológica y geotécnica de la Cuenca del Río Cesar, que permitió evaluar las inundaciones y desbordamientos en el curso del río y proponer alternativas de solución para evitar afectación en la población y sus bienes.

- Monitoreo de zonas inundadas con tecnologías geoespaciales, convenio realizado entre Colombia Humanitaria y el IGAC, cuyo objetivo es adquirir imágenes de sensores remotos para generar, mapear y monitorear la capa geográfica afectada por inundación mediante el uso de tecnologías geoespaciales, con el fin de fortalecer las entidades miembro del Sistema Nacional de la Prevención y Atención de Desastres.
Igualmente, se cuenta con gran variedad de trabajos escritos que han sido publicados, dado su carácter de relevancia e importancia para el estudio del riesgo de inundación en el país.

En los últimos años Colombia ha sufrido periodos de lluvia intensos que han generado un sinnúmero de emergencias y damnificados, convirtiéndose en un problema de relevancia nacional, que ha llevado a reestructurar los sistemas de gestión del riesgo y a su vez, las técnicas para la observación y prevención de este tipo de desastres. Debido a que las inundaciones abarcan generalmente grandes extensiones de terreno y la labor en campo para determinar las áreas de afectación se hace en muchos casos compleja, dadas las difíciles condiciones de acceso y seguridad, el uso de la teledetección y los sistemas de información geográfica surgen como una alternativa para observar este fenómeno ya que proporcionan un medio indirecto de análisis y evaluación de los efectos causados.

Para interpretar la zona de inundación en primer lugar se realiza un sinergismo con imágenes de diferentes características en su resolución y de esta forma lograr obtener una nueva imagen que aumente los niveles de detalle, sin embargo, dadas las condiciones topográficas de la zona que aceleran la evacuación de las aguas y al considerar la inundación como un fenómeno súbito, la mancha no es identificable debido a la diferencia de tiempo que existe entre la ocurrencia del fenómeno y la toma 
de la imagen de radar. En consecuencia, se busca, a través del Modelo Digital de Elevación extraer las curvas de nivel con un intervalo de 10 metros, para delimitar de forma aproximada la zona inundada. Finalmente, a través de una intersección entre las capas correspondientes a la predicación urbana y el área delimitada se realiza un estimativo del número de predios y áreas afectadas por la inundación.

\section{MATERIALES Y MÉTODOS}

\section{1. ANTECEDENTES DE LA INUNDACIÓN}

El municipio de Paz de Río y sus alrededores dada la complejidad geológica, tectónica y topográfica de la región, influenciado por los agentes atmosféricos, en diferentes ocasiones se ha visto afectado por deslizamientos de tierra, caída de rocas y desbordamiento de los ríos que han cobrado pérdida de vidas humanas y económicas; una de las catástrofes más fuertes que ha sufrido el municipio en los últimos años se presentó en abril del 2012, con el desbordamiento de los ríos Soapaga y Chicamocha, producto de la ola invernal que golpeó gran parte del territorio nacional.

El 13 de abril hacia las 12:30 p.m., con el incremento de las lluvias, se generó el crecimiento del caudal del Río Soapaga, desbordándose y abarcando predios de la empresa Acerías Paz del Río, situación que más tarde se agrava con el arrastre de sedimentación y material rocoso producto del deslizamiento Coloradales-Salitre, llevando a la salida total del cauce del río, cubriendo parte del casco urbano del municipio obligando a la evacuación inmediata de la comunidad en el área cercana afectada de los Barrios Colonial, Brisas del Soapaga, Venecia, causando daños físicos y pérdidas de viviendas, enseres, afectación de vías urbanas, redes de acueducto y alcantarillado (Figura 1). Así mismo, el aumento del caudal del río ocasionó la pérdida total del puente del sector El Charco que comunicaba la vía alterna, recientemente construida para ingreso al municipio; en el casco urbano se presenta colapso del puente que comunicaba a la empresa Acerías Paz del Río con el municipio.

Por otra parte, el 21 de abril de 2012 hacia las 10:20 p.m., se presentó un aumento del caudal del Río Chicamocha desbordándose e ingresando por las alcantarillas al casco urbano y nuevamente, el río Soapaga presentó desborde afectando las áreas antes mencionadas. Las principales afectaciones fueron 163 familias damnificadas, colapso de los gaviones del costado izquierdo del Río Chicamocha que protege al municipio, 50 familias de comerciantes afectados, taponamiento del sistema sanitario pluvial, colapso de los pozos de inspección, afectación de los colectores de alcantarillado, pérdidas de micro medidores, daños de las acometidas hidráulicas domiciliarias, colapso total del puente colgante peatonal que servía de comunicación de los municipios de Tasco-Paz de Río y afectación de cultivos y predios rurales de la región. [11] 

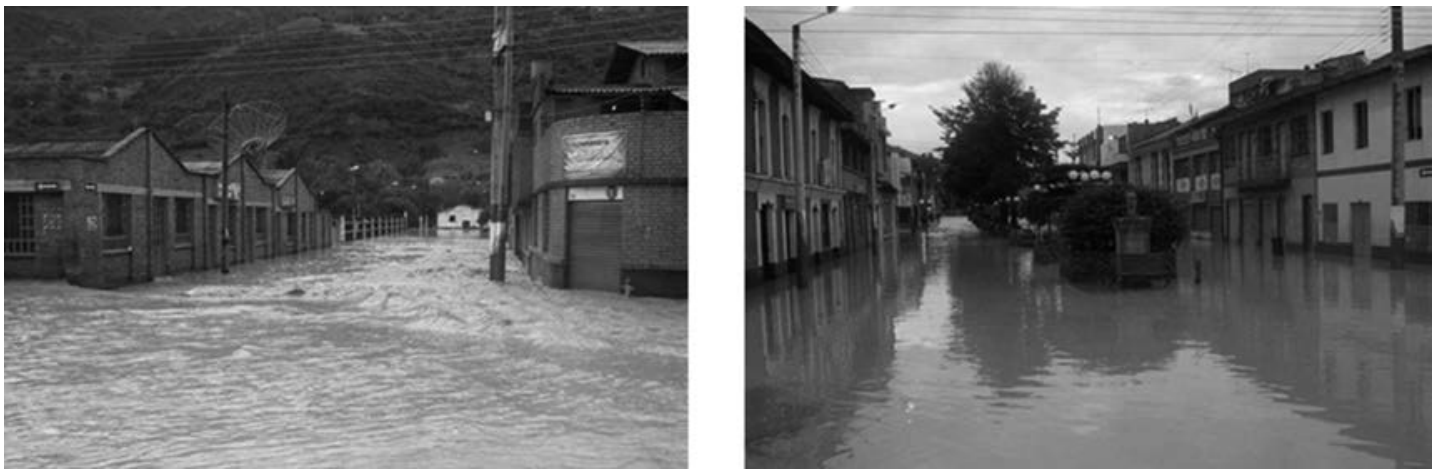

Figura 1. Inundación en zona urbana del municipio Paz de Río.

Fuente: Diario El Tiempo, 2012

\subsection{TELEDETECCIÓN}

La teledetección o detección a distancia se basa en el registro de la radiación electromagnética utilizando sensores remotos de diferentes tipos que no están en contacto físico con los objetos que emiten la energía (Cámaras fotográficas, escáners, sistemas de radar, etc.), y que son portados por diferentes vehículos de navegación aérea, unos ubicados en la atmósfera (Globos, aviones, helicópteros...) y otros fuera de la misma (Satélites, estaciones orbitales, naves espaciales...).

En el proceso de reconocimiento a distancia intervienen los siguientes componentes: $L a$ Energía, cuya fuente principal proviene del sol, si bien en la actualidad hay una cierta variedad de tipos de energía producida artificialmente en la tierra, sin que existan diferencias físicas significativas entre la energía natural y artificial; los elementos de la superficie terrestre (Suelo, agua, vegetación, construcciones...) y de La Atmósfera, a los que llega la energía y que la reflejan o absorben y emiten de acuerdo con sus características físicas; los sistemas sensores, instalados a bordo de los vehículos o plataformas aéreas, que captan la energía proveniente de la cobertura terrestre y la almacenan de diversas formas; finalmente, los sistemas de recepción de la información.

Una vez se desarrolla la fase de obtención de la información, es complementada con una segunda dedicada al análisis de la misma, un análisis a través del cual se obtiene la información buscada y en el que se pueden emplear las técnicas tradicionales de análisis visual de las imágenes y las más recientes para el tratamiento informático de los datos; en esta segunda fase puede ser necesaria también la realización de trabajos en campo para aclarar aquellos aspectos que no pueden ser resueltos únicamente a través del análisis de las fotografías aéreas [12].

\subsubsection{El Espectro Electromagnético}

La radiación electromagnética que existe en el universo, tanto la natural como la artifi- 
cial, es una forma dinámica de energía causada por la oscilación de una carga eléctrica, que se manifiesta únicamente cuando interactúa con la materia" [12].

La radiación electromagnética se caracteriza por su longitud de onda y por su frecuencia: La longitud de onda $(\lambda)$ es la distancia entre dos picos o dos senos de ondas sucesivas y la frecuencia ( $F$ ) el número de crestas o ciclos que pasan por un determinado punto en un segundo (Hercios, ciclos por segundo). La longitud de onda y la frecuencia se relacionan con la velocidad de la luz (V) del siguiente modo:

$$
\mathrm{V}=\mathrm{F} \lambda
$$

De donde se deduce que la frecuencia y la longitud de onda tienen una relación inversa y recíproca, además son directamente proporcionales a la velocidad. Al campo completo de la radiación electromagnética se le conoce como espectro electromagnético (Figura 2) y abarca desde las longitudes más cortas, que desde el punto de vista biológico pueden resultar letales, hasta las más largas, representadas por las ondas pasivas de radio.

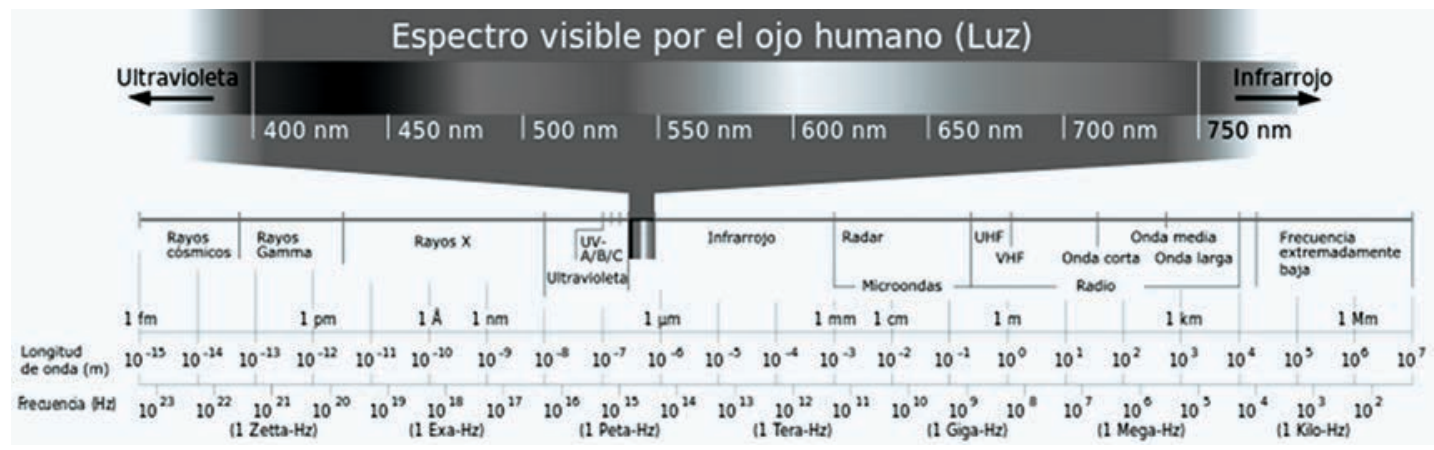

Figura 2. Espectro electromagnético $1 \mathrm{~nm}=10^{\wedge}-9 \mathrm{~m}$.

Fuente: Fernández, 2002.

Este conjunto se subdivide, con un cierto grado de arbitrariedad, en bandas que agrupan las longitudes de onda que cuentan con características similares; un ejemplo lo constituye la banda visible, que agrupa a las que pueden ser percibidas por el ojo humano.

Sin embargo, una gran parte de las radiaciones de distintas longitudes de onda no llegan a la superficie terrestre porque son absorbidas por la atmósfera (El ozono, por ejemplo, absorbe las cortas y el vapor de agua, las largas). Las radiaciones que atraviesan la atmósfera lo hacen aprovechando la existencia de las llamadas ventanas atmosféricas. Una de ellas sería la correspondiente a la luz visible (400 a 700 nanómetros) y a algunas radiaciones infrarrojas y ultravioletas, lo que se conoce 
como región óptica del espectro o espectro fotográfico.

\subsection{LOCALIZACIÓN Y DESCIPCIÓN GENERAL DEL ÁREA DE ESTUDIO}

El municipio de Paz de Río se encuentra ubicado en la región norte del Departamento de Boyacá sobre el margen de los ríos Chicamocha y Soapaga a una altura de 2200 msnm., posee una temperatura promedio de $16^{\circ} \mathrm{C}$, y cuenta con una extensión total de $117 \mathrm{Km}^{2}$, de los cuales el área urbana está constituida por $38.7 \mathrm{Km}^{2}$, y un total de $77.3 \mathrm{Km}^{2}$ de área rural. El sector urbano lo constituyen 9 barrios (Brisas del Soapaga, Buenos Aires, Colonial, Gaitán, La Paz, Metrópolis, Progreso, Santa Teresa y Venecia); por otra parte según el IGAC, el sector rural lo integran 10 veredas así: Carichana, Chitagoto, Chorrera, Colacote, Piedra Gorda, Salitre, Sibaria, Soapaga, Socotacito y Tiza. [13].

Topográficamente el área del municipio de Paz de Río está controlada por la litología y la tectónica, heredando rasgos de colinas y montañas cuyas pendientes oscilan entre $25 \%$ y $80 \%$. La acción de los diferentes agentes erosivos, ha afectado los rasgos topográficos, poniendo de manifiesto las estructuras íntimamente relacionadas con ellos. A lo largo de la cuenca del Río Chicamocha se observa que las características topográficas dependen fundamentalmente, de la estructura y secundariamente de la dinámica; se presentan terrenos con elevaciones entre los 2000 y 3600 m.s.n.m., en términos generales el $75 \%$ de este sector presenta pendientes con dirección hacia el
Río Chicamocha, el 30\% restante se inclina hacia el Río Soapaga siendo las vertientes principales del área municipal.

De forma genérica en el área urbana los suelos presentan altas pendientes en casi la totalidad de su área y en especial hacia la parte del Colegio Técnico y en los barrios Gaitán, Buenos Aires, La Paz, Colonial y Metrópolis. Presentan pedregocidad superficial y una textura franco arenosa [14]; así mismo, para los barrios Colonial, Brisas del Soapaga y Venecia, las elevaciones se encuentran entre los 2210 y 2220 m.s.n.m.

El área específica objeto de estudio se encuentra localizada sobre la parte oriental del centro poblado principal del municipio, cuyas coordenadas Gauss Krûger (Equivalentes a la proyección UTM) aproximadas son $X=1.146 .000,1.149 .000$ metros y $Y=1.153 .000,1.157 .000$ metros, correspondientes al recuadro de la parte derecha de la (Figura 3), se seleccionó esta zona dado que la inundación se presentó específicamente en los sectores correspondientes a los barrios Colonial, Brisas del Soapaga y Venecia.

Según el Esquema de Ordenamiento Territorial (EOT) del municipio adoptado en el año 2007, el número de viviendas total existentes en los barrios afectados por la inundación es de 316 (Tabla 1), en donde el número promedio de personas por hogar es de 3,4 [14]; es decir, si se realiza el cálculo, se tiene que el número aproximado de población afectada por la inundación es de 884 personas. 
Tabla 1. Número de viviendas en los barrios afectados por la inundación.

\begin{tabular}{|l|c|c|c|c|}
\hline \multicolumn{1}{|c|}{ BARRIO } & $\begin{array}{c}\text { No. VIVIENDAS } \\
\text { PROPIAS }\end{array}$ & $\begin{array}{c}\text { No. VIVIENDAS } \\
\text { ARRENDADAS }\end{array}$ & $\begin{array}{c}\text { No. VIVIENDAS } \\
\text { OTRA FORMA }\end{array}$ & $\begin{array}{c}\text { TOTAL } \\
\text { VIVIENDAS }\end{array}$ \\
\hline COLONIAL & 44 & 57 & 14 & 115 \\
\hline VENECIA & 37 & 54 & 28 & 119 \\
\hline BRISAS DEL SOAPAGA & 31 & 28 & 23 & 82 \\
\hline TOTAL & $\mathbf{1 1 2}$ & $\mathbf{1 3 9}$ & $\mathbf{6 5}$ & $\mathbf{3 1 6}$ \\
\hline
\end{tabular}

Fuente: EOT, 2007.

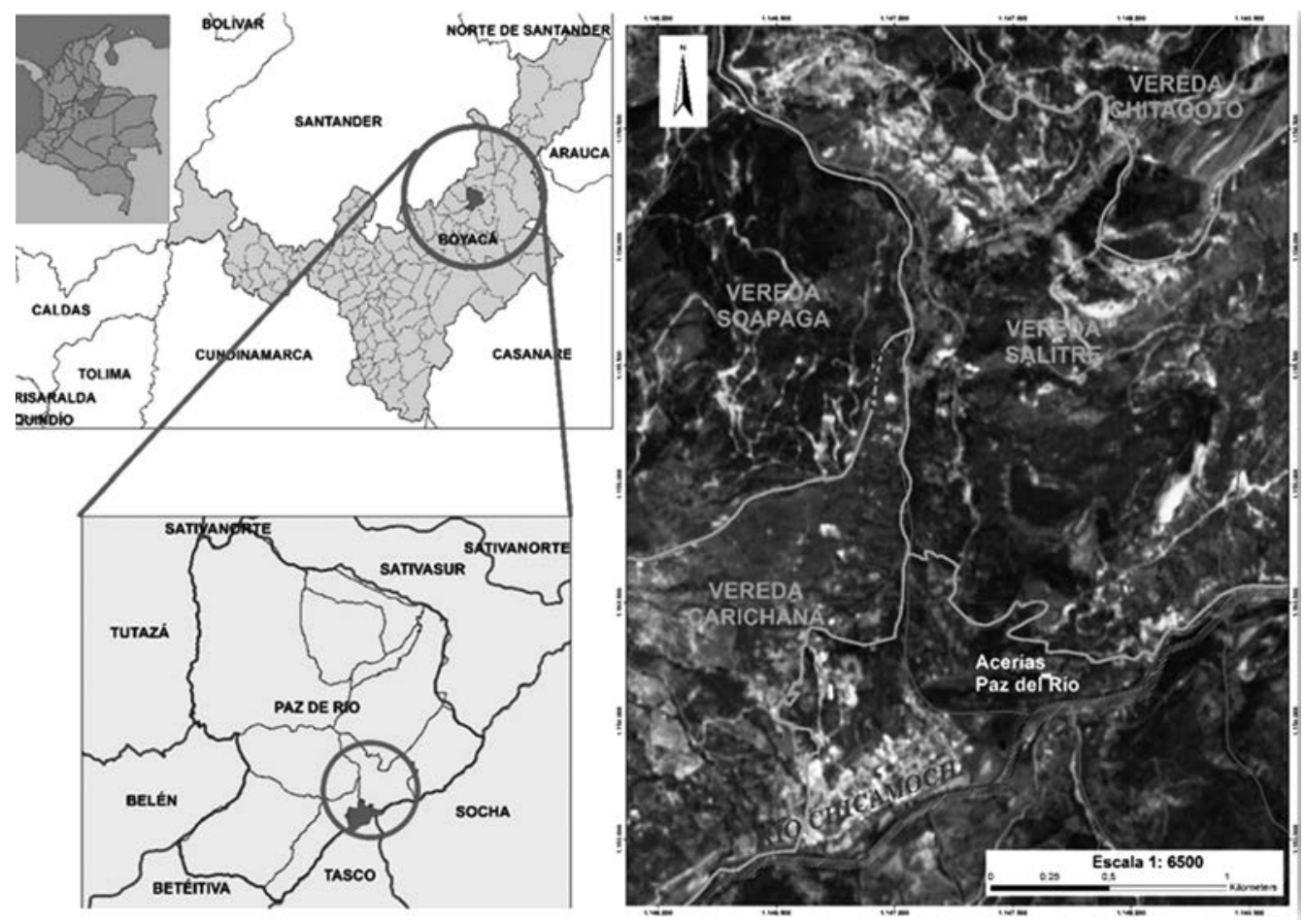

Figura 3. Localización de la zona de estudio.

Fuente: Autores, 2013.

\subsection{MATERIALES}

Se trabajó con información fuente proveniente del Instituto Geográfico Agustín Codazzi IGAC, el cual proporcionó lo concerniente a las imágenes de satélite, se uti- lizaron dos tipos de imágenes, una imagen óptica adquirida del sistema satelital RapidEye y una imagen de radar del programa CosmoSkymed, los datos principales de cada una de las imágenes se muestran a continuación (Tabla 2). 
Tabla 2. Datos principales de las imágenes.

\begin{tabular}{|l|c|c|}
\hline \multicolumn{1}{|c|}{ IMAGEN } & RapidEye & CosmoSkymed \\
\hline Resolución Espacial & 7 metros & 5 metros \\
\hline Resolución Temporal & 1 a 5 dias & 10 horas \\
\hline Resolución Espectral & 5 Bandas (RGB, Red, Edge, IRC) & 2 Bandas (X) \\
\hline Resolución Radiométrica & 12 bits/pixel & 16 bits/pixel \\
\hline Tamaño de Escena & $77 \mathrm{~km}$ & $40 \mathrm{~km}$ \\
\hline Tamaño en Disco & $1234.62 \mathrm{MB}$ & $395.09 \mathrm{MB}$ \\
\hline Fecha de Toma & $08 / 12 / 2009$ & $25 / 04 / 2012$ \\
\hline
\end{tabular}

Fuente: Autores, 2013.

Cabe anotar que las dos imágenes se encuentran en el mismo sistema de referencia cuyos parámetros son:

- Tipo de proyección: Transverse Mercator.

- Elipsoide de referencia: GRS 1980.

- Datum: SIRGAS.

Adicionalmente, se recopiló información relevante como lo es el Modelo Digital de Elevación (DEM) para toda Colombia con una resolución de 30 metros, la prediación a nivel urbano del municipio con vigencia catastral del año 2009 en formato File Geodatabase, la cual se obtuvo del repositorio de datos del Instituto Geográfico
Agustín Codazzi (Subdirección de Catastro), cartografía básica a escala 1:100.000 del municipio y sus alrededores, adquirida en formato File Geodatabase (IGAC, subdirección de Geografía y Cartografía), así mismo, todo lo que corresponde a los límites político administrativos (Municipales, veredales, centros poblados, etc.), en formato Shape y File Geodatabase (IGAC, subdirección de Geografía y Cartografía), y finalmente, los documentos correspondientes al Plan de Desarrollo Municipal vigente (2012-2015), y el Esquema de Ordenamiento Teritorial (EOT) adoptado en el año 2007.

\subsection{METODOLOGÍA}

A continuación se muestra el diagrama de flujo que se siguió para la consecución del estudio (Figura 4). 


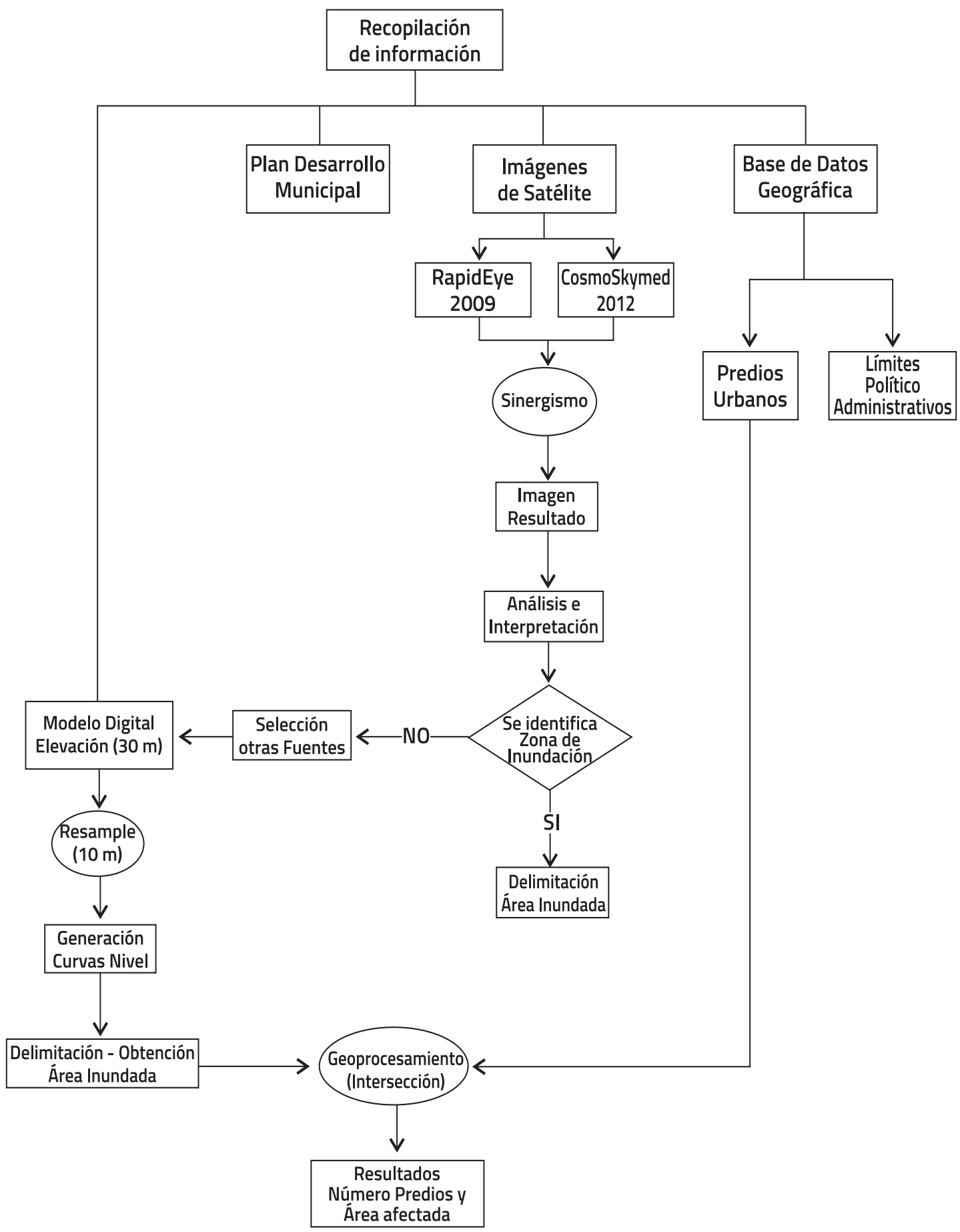

Figura 4. Diagrama de flujo para la metodología.

Fuente: Autores, 2013. 
Para establecer el área de inundación provocado por el río Soapaga (Afluente del río Chicamocha) se hace uso de un sinergismo, para aprovechar las características espectrales de la imagen RapidEye, ya que en la imagen de radar no se visualiza claramente el área de inundación. Es importante resaltar que la única imagen con información posterior a este fenómeno es la obtenida por el sensor CosmoSkymed empleado para imágenes de radar. Con ayuda del software Erdas Imagine 2010 y la herramienta Resolution Merge se procede a realizar el sinergismo.

Para este caso se utilizó el método Brovey Transform, el cual fue desarrollado para aumentar los contrastes visuales en las zonas finas, bajas y altas del histograma de las imágenes, es decir para proporcionar el contraste en las sombras, agua y áreas de alta reflectancia. Este método no debe ser usado si se desea conservar la radiometría de la escena original.

El método Brovey también permite controlar la combinación RGB que se desea obtener, para este caso se utilizaron los canales $4,5,3$ que resalta las zonas de humedad y cuerpos de agua en un tono magenta ( $\mathrm{Fi}$ gura 5). Finalmente, se obtiene una imagen multiespectral con características acordes a las necesidades del estudio.

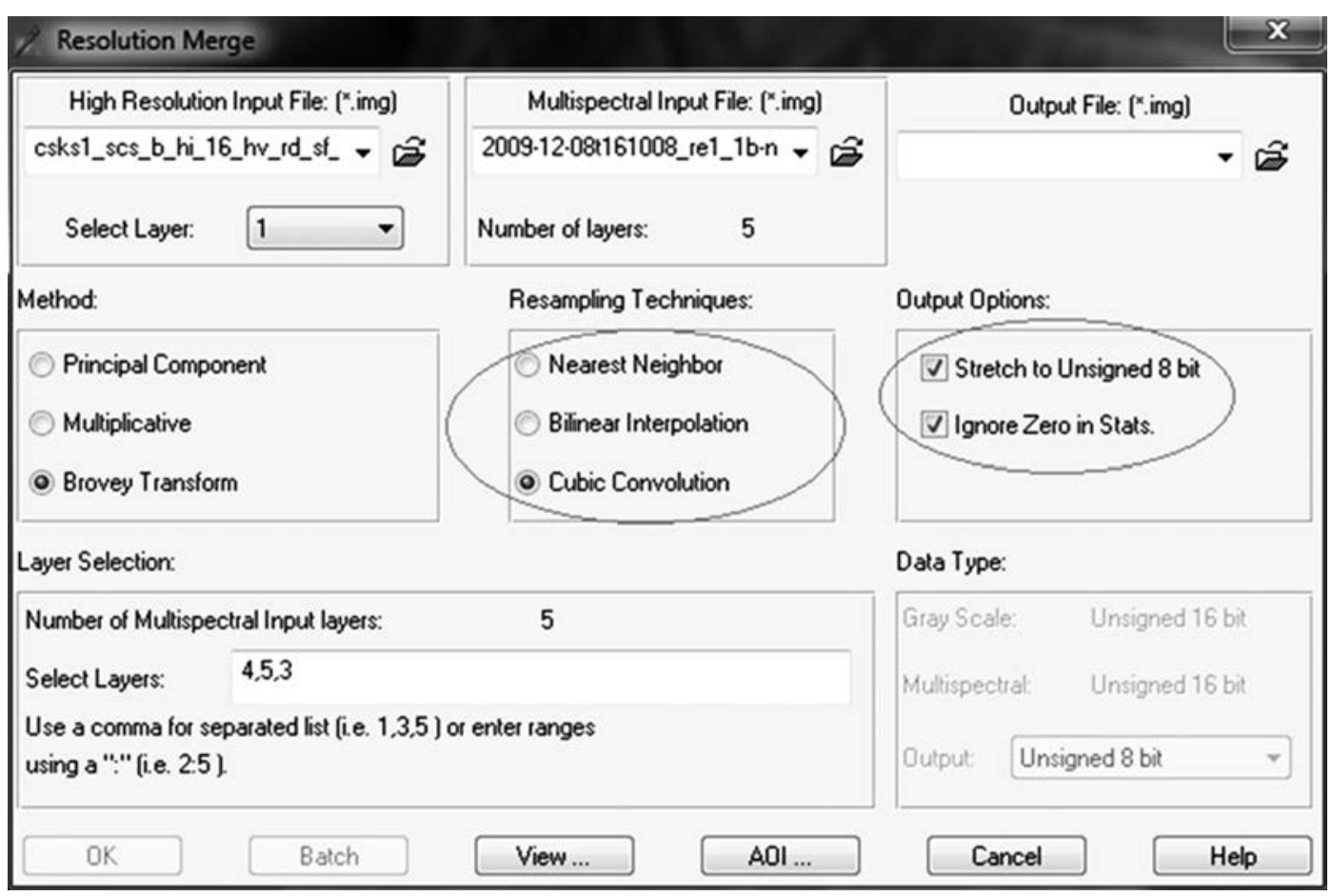

Figura 5. Herramienta "Resolution Merge" para la obtención del sinergismo.

Fuente: Autores, 2013. 
Una vez interpretado el sinergismo se deduce que no es posible identificar el área inundable ya que la topografía de la zona es pendiente e influyó para que el agua drenara rápidamente. En consecuencia, la imagen no permite identificar la inundación, ya que existe una diferencia de 12 días entre la ocurrencia del evento y la toma de la imagen de radar. Dado lo anterior, se busca una nueva alternativa para delimitar de forma aproximada la posible área de inundación teniendo en cuenta la topografía de la zona, para ello se hace uso del Modelo Digital de Elevación (DEM) de Colombia a 30 metros de resolución.

Tomando como base el Modelo Digital de Elevación (DEM) se hace un corte que delimita aproximadamente la zona de estudio y con ayuda de la herramienta $R e$ sample de Arctoolbox se genera un nuevo DEM de 10 metros de resolución, el cual permite un mayor detalle de la topografía (Figura 6).

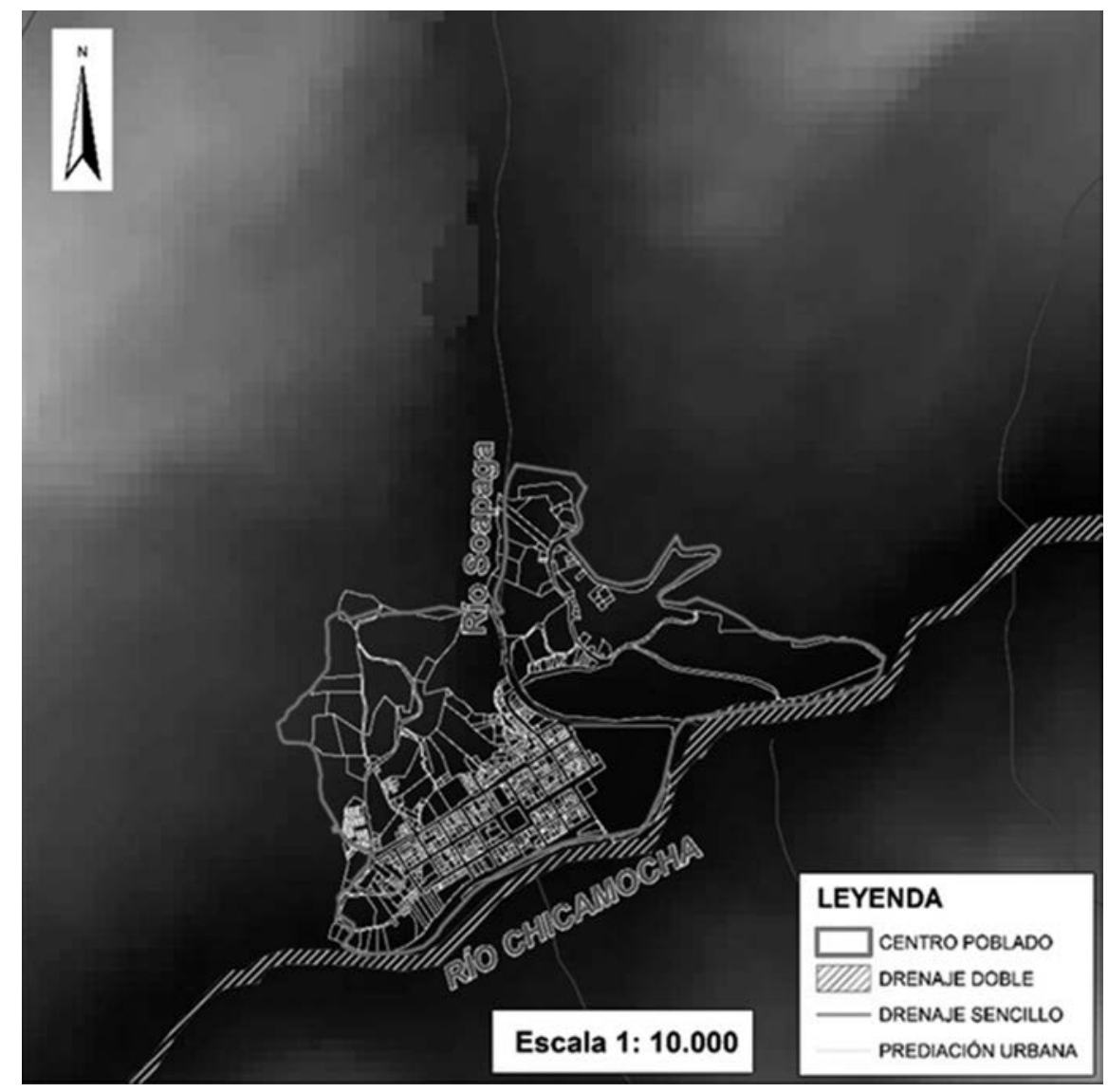

Figura 6. DEM de la zona de estudio a 10 metros de resolución.

Fuente: Autores, 2013. 
Teniendo como base el DEM de 10 metros de resolución generado, se extraen las curvas de nivel con ayuda de la herramienta Contour de Arctoolbox (Figura 7) y se delimita el área aproximada de inundación tomando como referencia la cota 2210 metros de altura y un sector del Río Chicamocha.

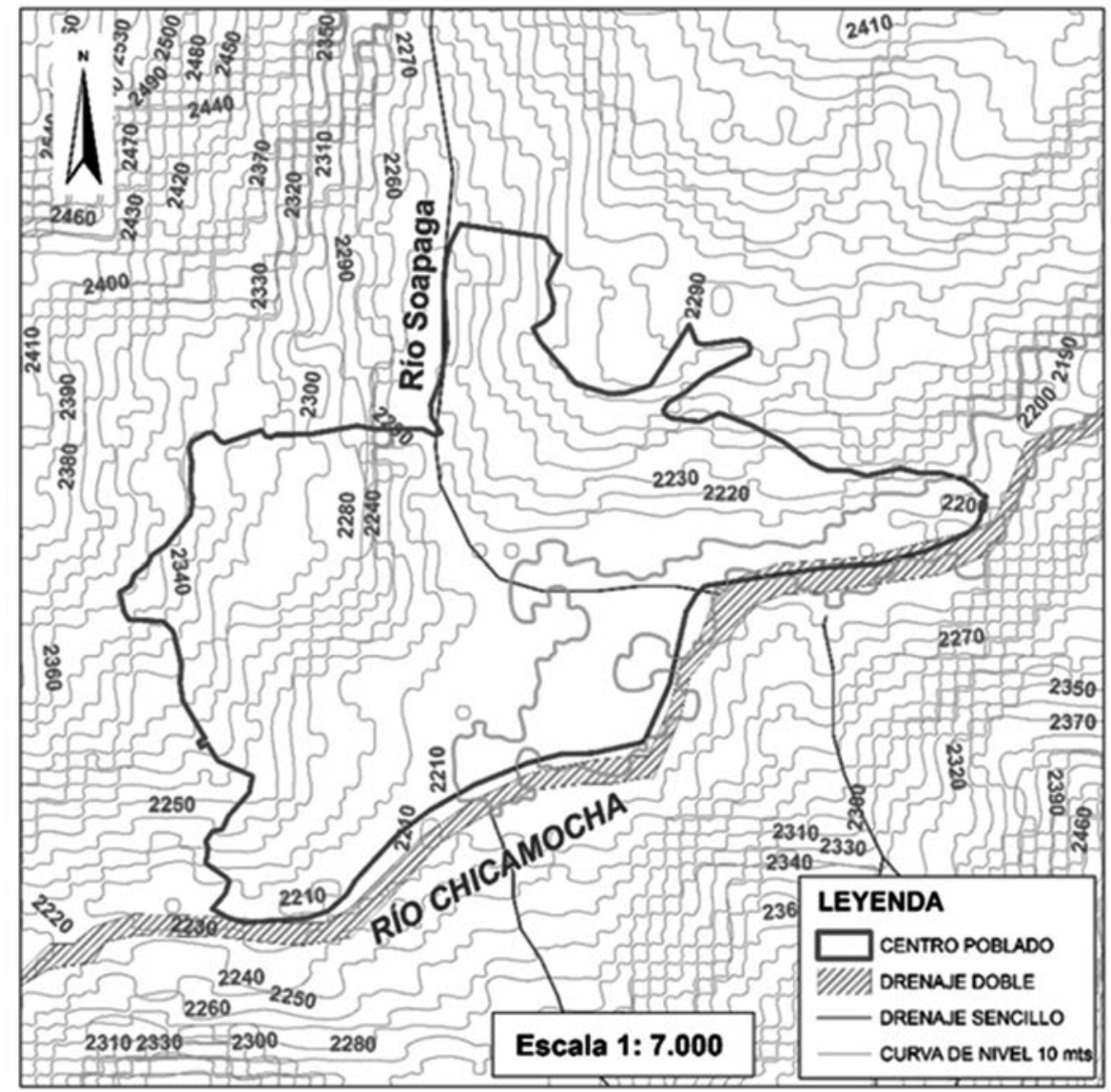

Figura 7. Curvas de nivel - Selección de cota 2210 metros.

Fuente: Autores, 2013.

Con el insumo correspondiente a la prediación urbana y el polígono trazado con el área inundada se procede a realizar un geoprocesamiento tipo intersección entre dichas capas, haciendo uso de la herramienta
ArcToolbox, con la finalidad de cuantificar el número de predios y áreas afectadas por la inundación. Este resultado se almacena en un nuevo feature class tipo polígono llamado Area_Afectada_Urbana. 


\section{RESULTADOS Y ANÁLISIS}

Al tomar la imagen del sensor RapidEye por separado y llevar a cabo un análisis de las coberturas más representativas se puede observar que para la combinación RGB $(5,4,3)$, la cobertura correspondiente a zonas construidas (Centro poblado) se identifica claramente en tonos claros, de manera similar ocurre con la cobertura de tierras eriales o zonas con procesos erosivos, los tonos café, naranja y marrón muestran claramente zonas pertenecientes a vegetación ya sea bosque (Tonos naranja) o vegetación herbácea descubierta (Tonos café). Los cuerpos de agua se visualizan en tonos azules oscuros, y en cuanto a las zonas correspondientes a los predios de la empresa Acerías Paz de Río, se identifican en tonos completamente oscuros (Negro). En el caso de las vías éstas toman tonos grises claros, muy similar a como se visualiza la cobertura de áreas construidas. (Figura 8).

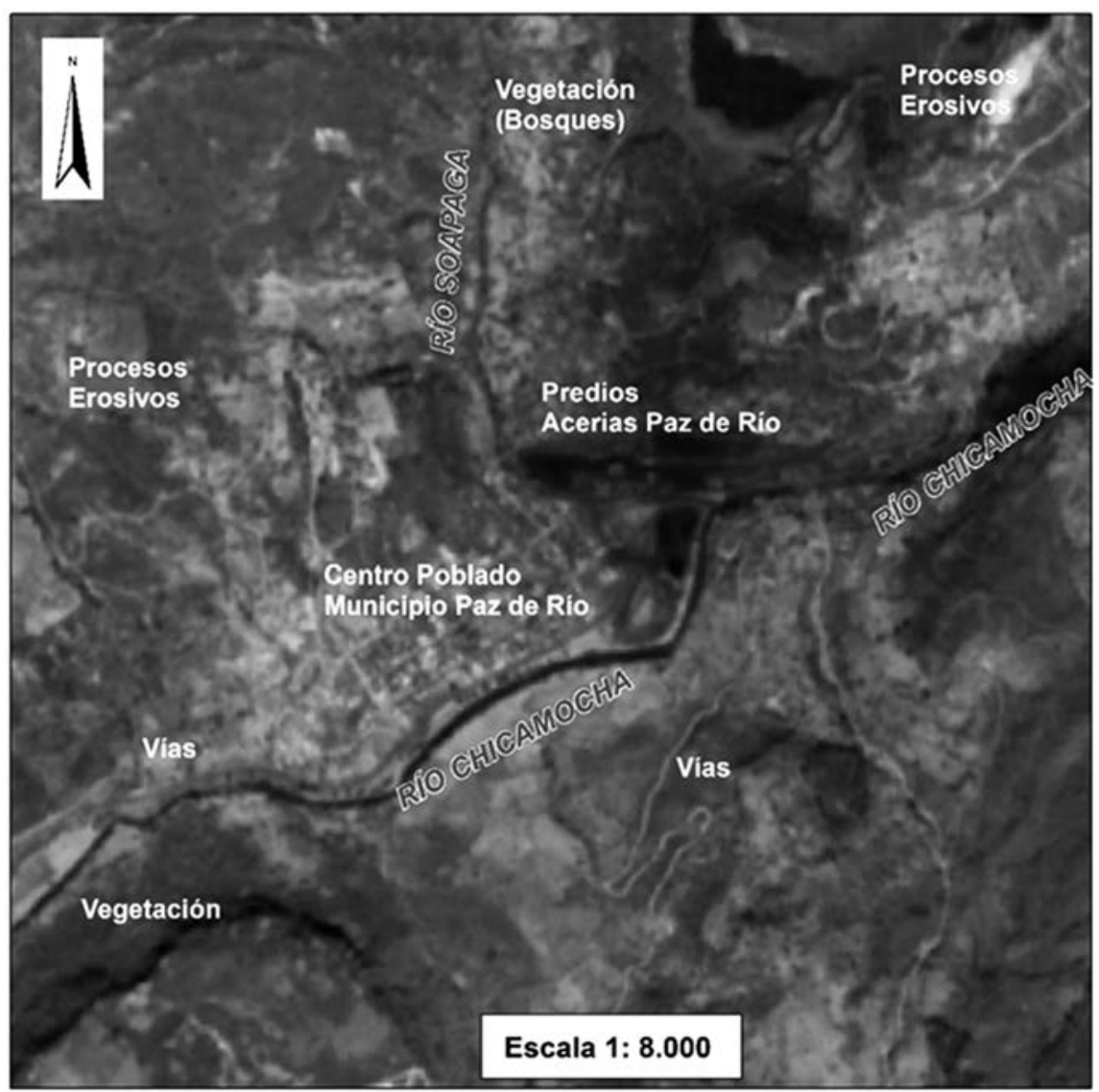

Figura 8. Imagen RapidEye de la zona de estudio, combinación RGB $(5,4,3)$.

Fuente: Autores, 2013. 
Para determinar el área de inundación aproximada se obtuvo inicialmente un sinergismo de imágenes en el cual se busca identificar la mancha de agua, pero al ser la imagen de radar capturada en un tiempo posterior a la fecha de inundación y teniendo en cuenta que el evento cubrió un área no muy extensa, el uso de esta imagen no es aplicable para este estudio, sin embargo, en el sinergismo al igual que en la imagen RapidEye, se logran identificar algunas coberturas representativas de la zona de estudio, mediante la interpretación de los diferentes tonos existentes en la imagen, tal es el caso de los tonos claros, los cuales evidencian presencia de procesos erosivos y construcciones, las áreas de color violeta y morado varían entre zonas de bosques y vegetación de poca altura, así mismo, las zonas con tonos verdes más oscuros poseen contenido de agua (Ríos Chicamocha y Soapaga), y finalmente, las áreas que toman un color café, corresponden a los predios pertenecientes a la empresa Acerías Paz de Río (Figura 9).

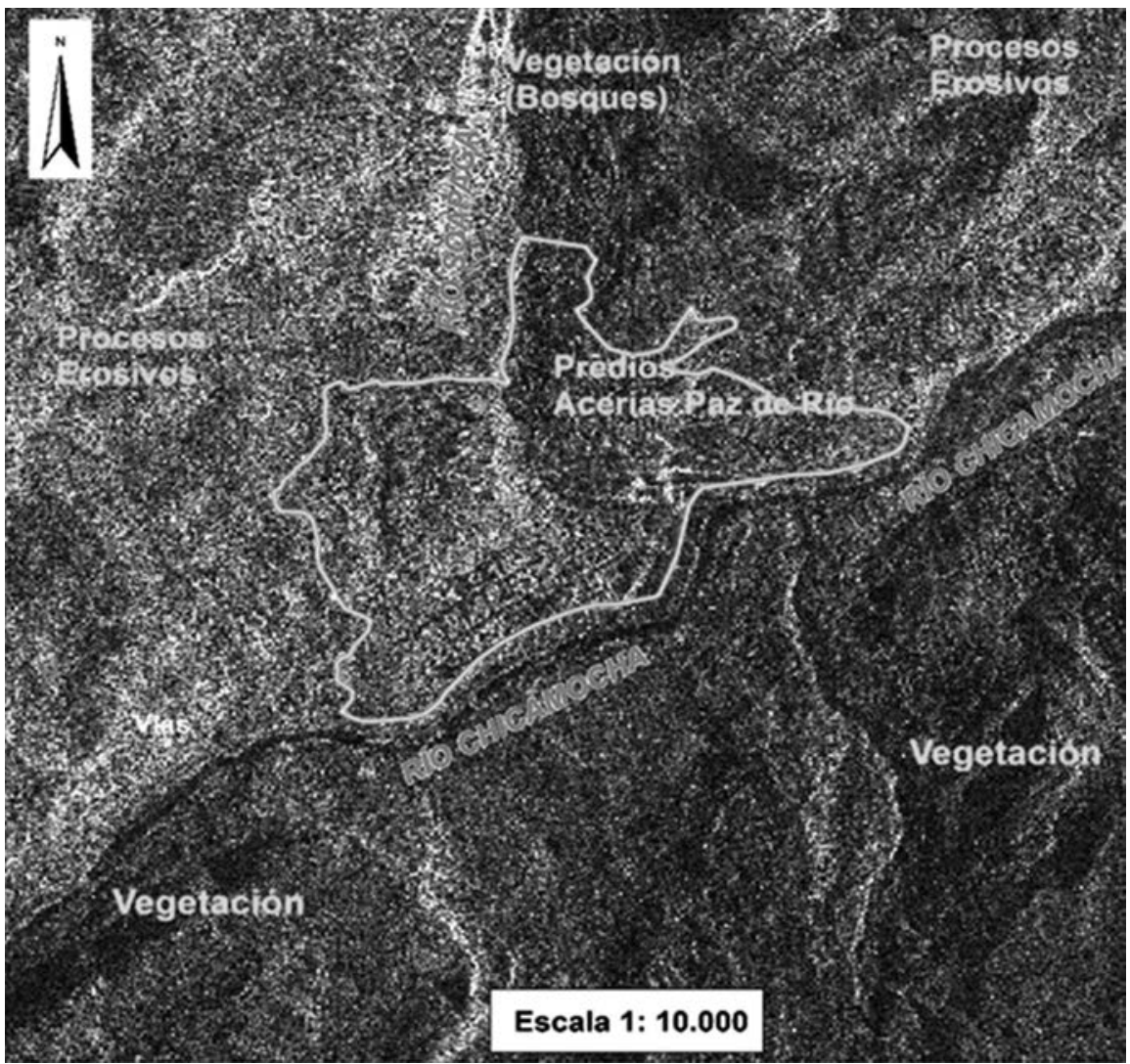

Figura 9. Sinergismo entre imágenes RapiEye y CosmoSkymed.

Fuente: Autores, 2013. 


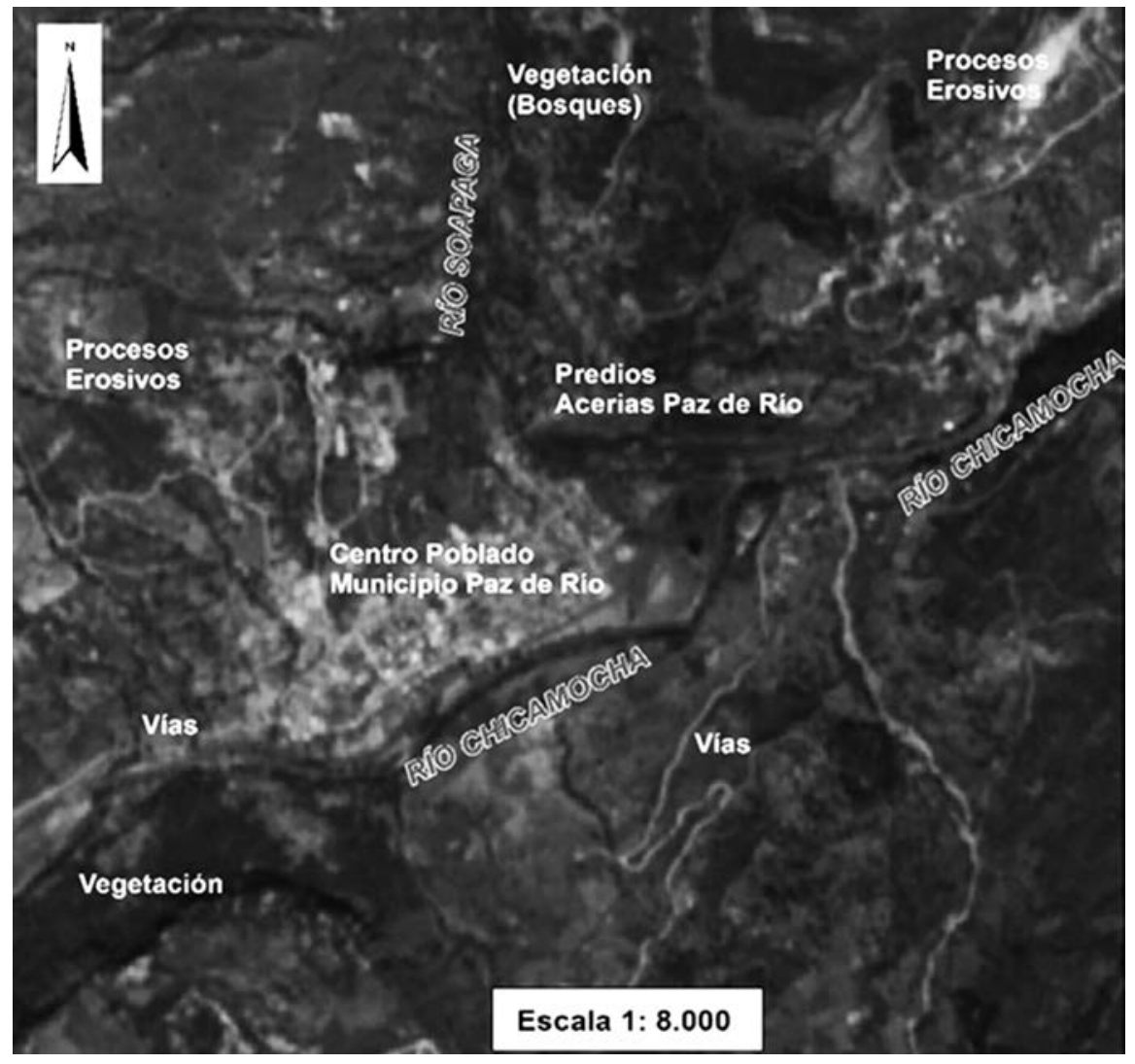

Figura 10. Imagen RapidEye de la zona de estudio, combinación verdadero color RGB $(3,2,1)$.

Fuente: Autores, 2013.

De igual forma, la interpretación de las coberturas realizada anteriormente se logra constatar en la imagen cuya combinación se encuentra en verdadero color RGB $(3,2,1)$. (Figura 10).

Una vez descartado el sinergismo se obtiene el área de inundación a partir de la extracción de las curvas de nivel a un intervalo de 10 metros.
Para delimitar el área probable de inundación se tomó como referencia la cota de 2210 metros de altura, ya que se estima que el nivel del agua no excedió los dos metros de altura con respecto a la altura aproximada del Río Soapaga y a su vez la información registrada en el plan de desarrollo del municipio, indica que los barrios y predios afectados por la inundación coinciden con el área probable delimitada (Figura 11). Para el área total delimitada se obtuvo un total de $126.564,59 \mathrm{~m}^{2}$. 


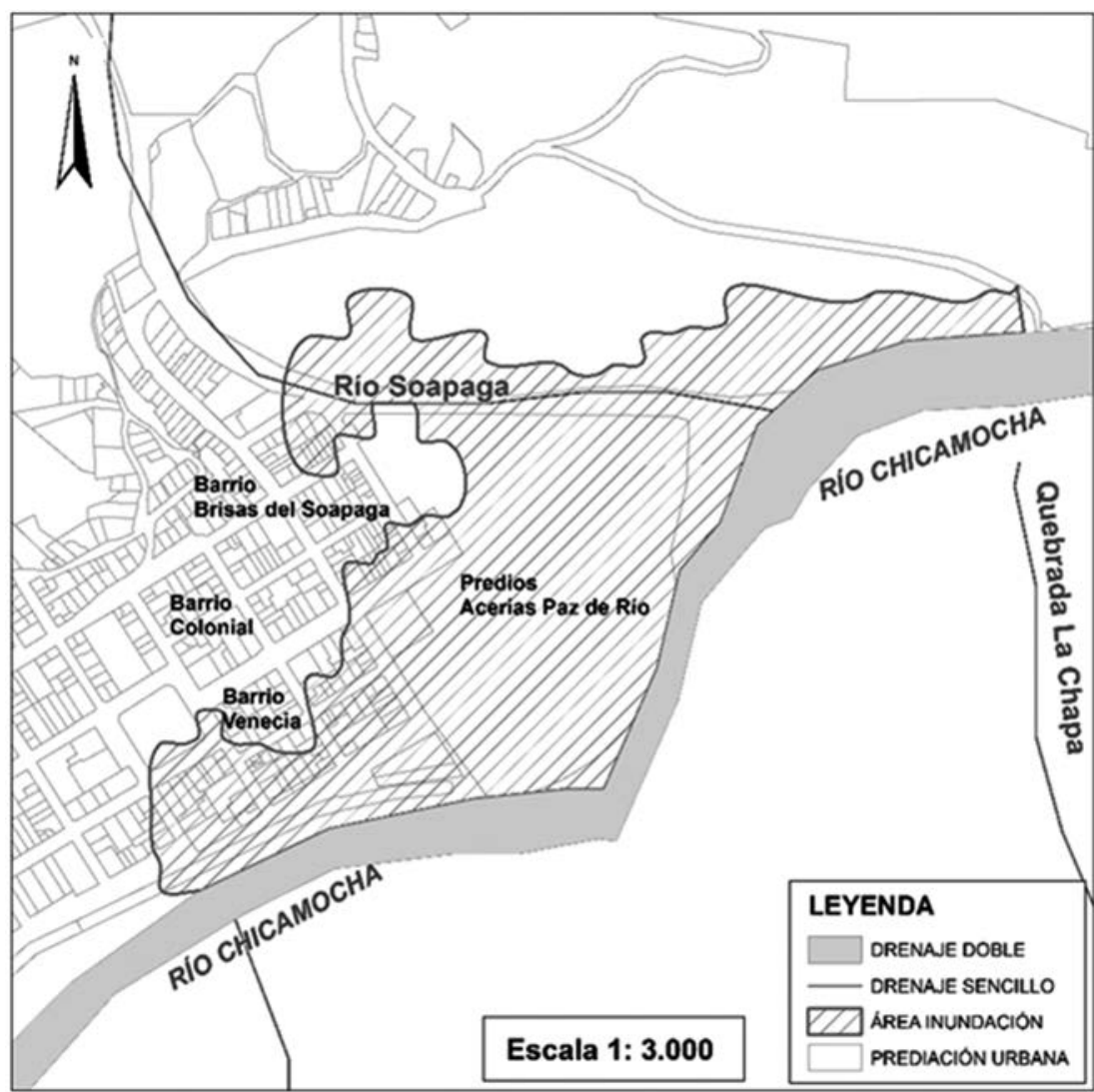

Figura 11. Área de inundación delimitada siguiendo la curva 2210 metros.

Fuente: Autores, 2013.

Como parte de los resultados obtenidos y mediante el programa Google Earth, se tomando como insumo principal las cur- llevó a cabo una captura en vista 3D de vas de nivel extraídas a una equidistan- la zona de estudio, encontrándose que cia de 10 metros, se generó la superficie existe el mismo comportamiento entre la topográfica, donde se puede apreciar en topografía generada a través de las curuna vista 3D, el relieve aproximado de la vas de nivel y la imagen de alta resolución zona objeto de estudio [15]. Así mismo, existente en el programa (Figura 12). 

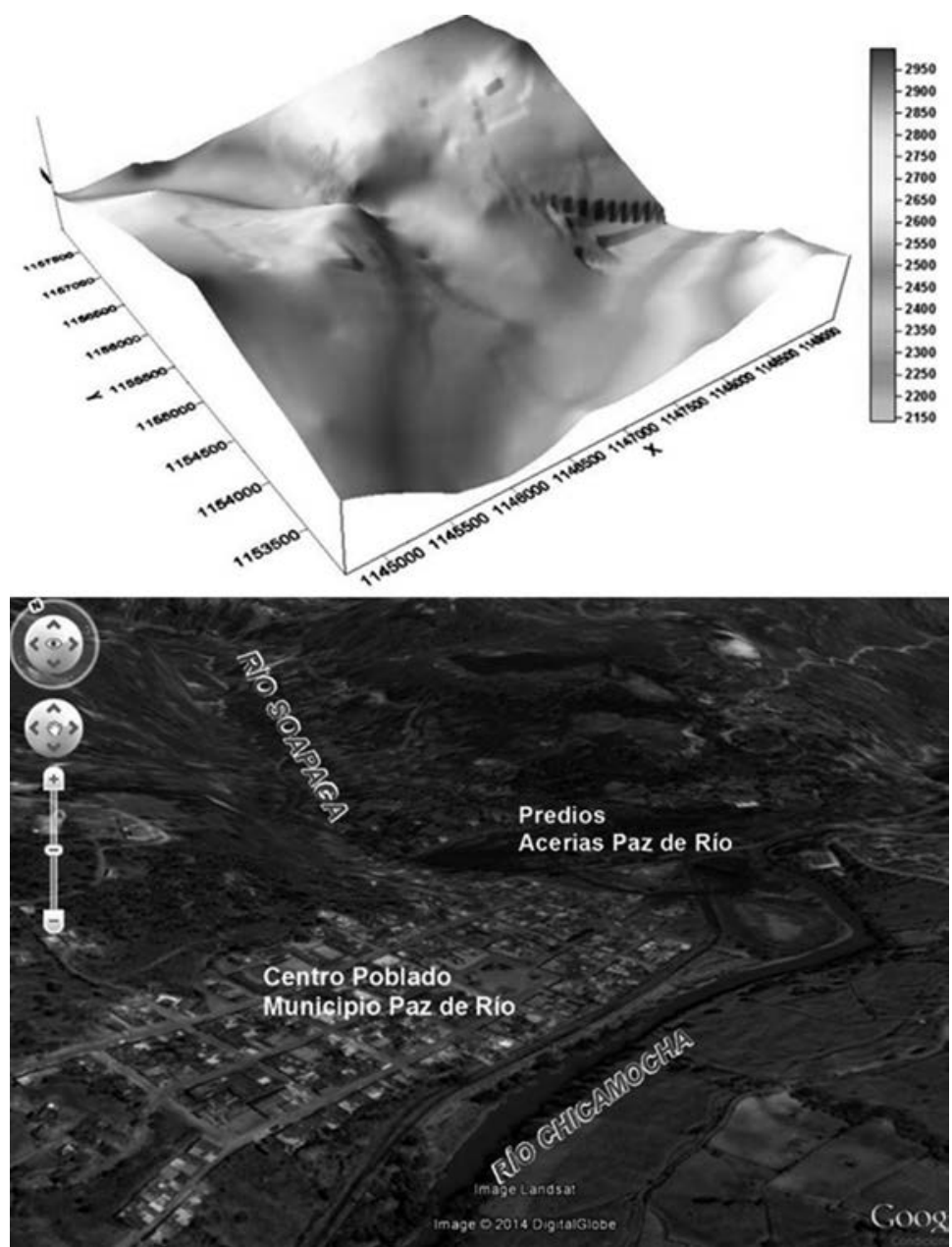

Figura 12. Superficie topográficas comparadas; parte superior, superficie aproximada generada a través de las curvas de nivel cada 10 metros; parte inferior, captura real de la zona de estudio.

Fuente: Autores, 2013; Google Earth, 2013.

Finalmente, con ayuda de un geoprocesamiento se realiza una intersección entre la capa predial urbana y el área delimitada, en donde se obtiene un resultado de 114 predios afectados, correspondiente al 13,6\% del total de predios existentes en el casco urbano (838) y un área total afectada de $97.949,89 \mathrm{~m}^{2}$, que corresponde al $11,12 \%$ con respecto al área total del centro poblado $\left(880.390,67 \mathrm{~m}^{2}\right)$ (Figuras 13 y 14$)$.
Cabe anotar que no todos los 114 predios se vieron afectados en la totalidad de su área, es decir, algunos presentaron afectación en tan solo una parte de ésta; así mismo, en el cálculo del área total afectada también se involucran las áreas correspondientes a vías, porciones del malecón y rondas pertenecientes a los Ríos Soapaga y Chicamocha. 


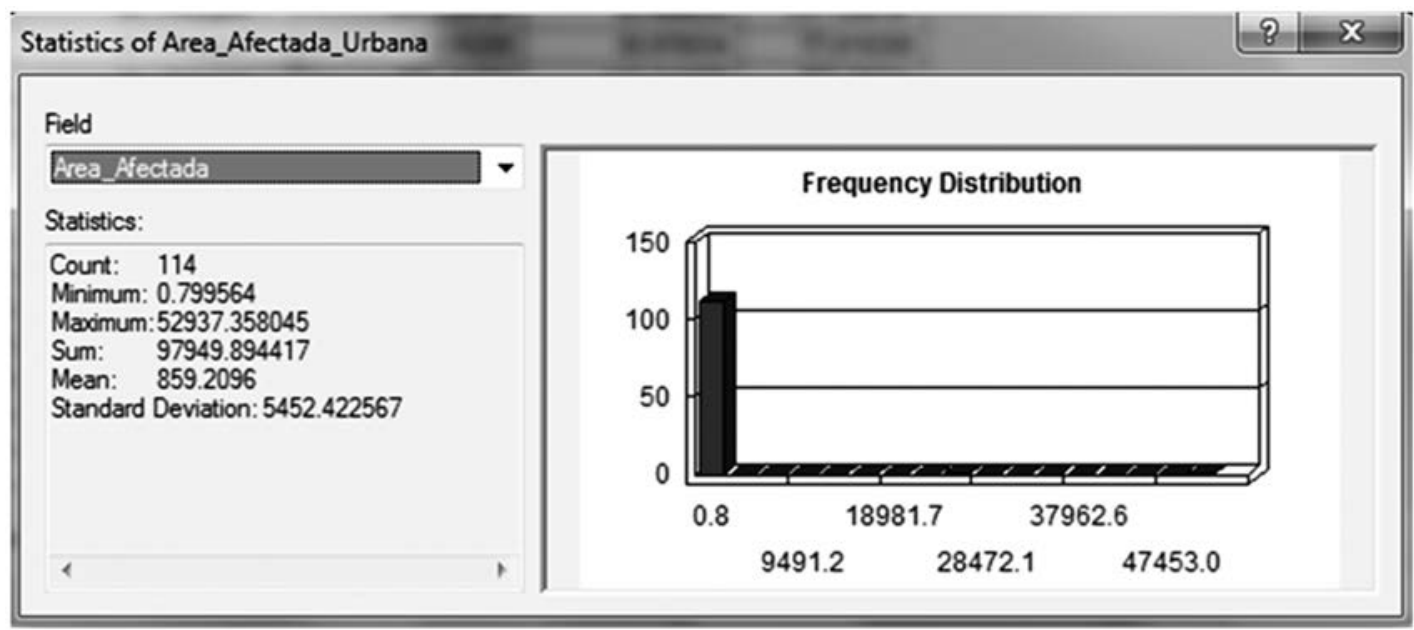

Figura 13. Estadísticas de área y número de predios afectados.

Fuente: Autores, 2013.

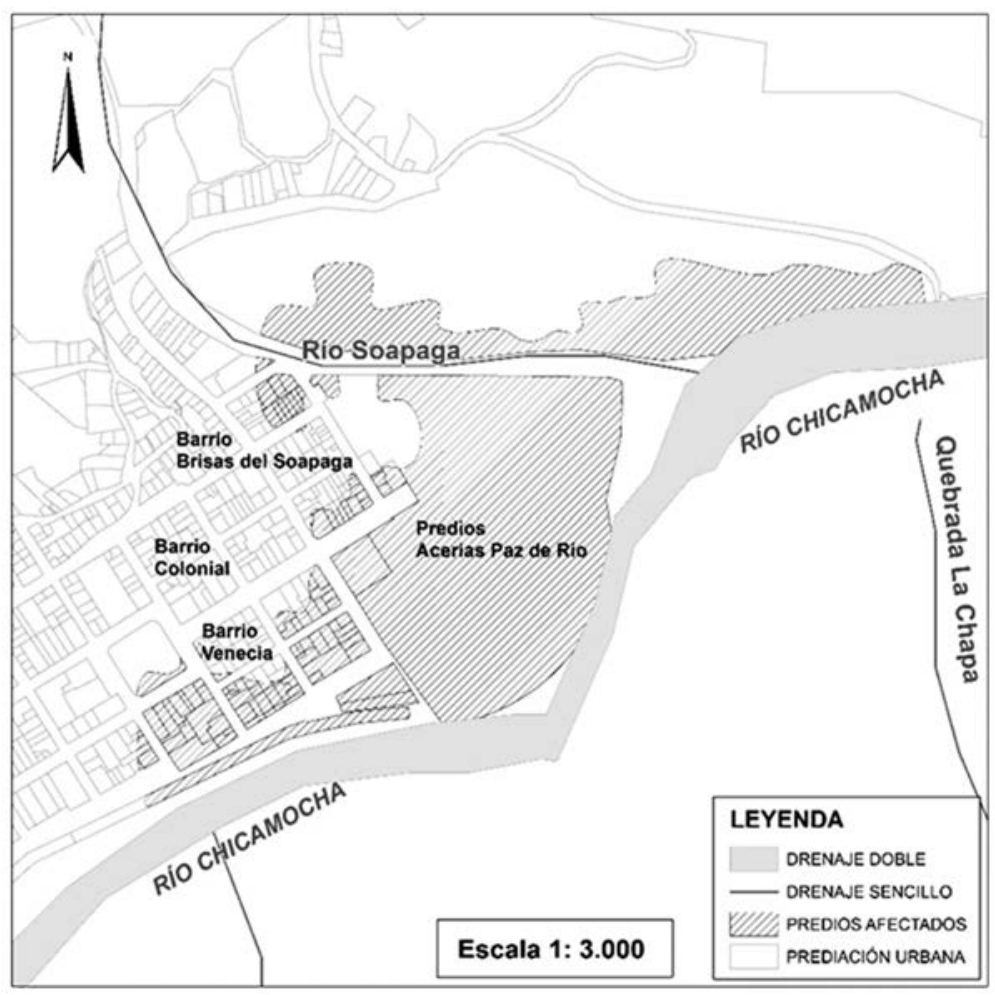

Figura 14. Predios afectados por inundación.

Fuente: Autores, 2013. 


\section{CONCLUSIONES}

A través del modelo digital de elevación se obtuvo un criterio claro del comportamiento del relieve con el fin de conocer la zona probable en la que se depositó la inundación y a su vez determinar la cota máxima a la que podía llegar la inundación, tomando como referencia el nivel medio del Río Soapaga, que para el caso de estudio no excedió los dos metros de altura. De esta manera, se puede determinar que los DEM's se convierten en un insumo fundamental para este tipo de estudios, que apoyan en gran medida la labor de campo o simplemente en aquellos casos en los cuales no se lleva a cabo dicha labor.

Aprovechando la herramienta SIG del geoprocesamiento, se logró establecer que el número total de predios afectados por la inundación es de 114 , correspondiente al $13,6 \%$ del total de predios existentes en el casco urbano (838) y un área total afectada de $97.949,89 \mathrm{~m}^{2}$, que corresponde al $11,12 \%$ con respecto al área total del centro poblado $\left(880.390,67 \mathrm{~m}^{2}\right)$, así mismo, a través de dicha intersección se constató la afectación de los tres barrios (Colonial, Brisas de Soapaga y Venecia), dado que coincide con el reporte consignado en el Plan de Desarrollo Municipal.

No fue posible identificar el área de inundación en el sinergismo, debido a que el fenómeno ocurrido es considerado como súbito, dada la topografía montañosa de la zona que produce la desaparición casi instantánea del fenómeno, con lo cual la imagen de radar no es la más óptima para este tipo de estudios, siendo más aplicable a aquellos trabajos que involucren una mayor extensión y en zonas donde el relieve permita el estancamiento de cuerpos de agua por largos periodos de tiempo. Sin embargo, en el sinergismo al igual que en la imagen RapidEye, se lograron identificar algunas coberturas representativas de la zona de estudio, mediante la interpretación de los diferentes tonos existentes en la imágenes y llevando a cabo una serie de combinaciones entre bandas, así, las coberturas que se lograron identificar con mayor detalle corresponden a zonas construidas, tierras eriales o procesos erosivos, cuerpos de agua principales (Ríos Chicamocha y Soapaga), bosques y vegetación herbácea descubierta, vías y finalmente los predios pertenecientes a la empresa Acerías Paz de Río.

Como ejercicio de verificación, se realizó una comparación entre la superficie topográfica generada a partir de las curvas de nivel a una equidistancia de 10 metros y la vista en 3D real de la zona (Imagen Google Earth), obteniéndose de esta forma igual comportamiento entre las dos superficies, en lo concerniente a la topografía y el relieve de la zona objeto de estudio.

La inundación que se presentó el 13 de abril de 2012 fue causada por el estancamiento de material rocoso en el río Soapaga y por esta razón un estudio a futuro sería conocer el volumen de material que permita modelar una inundación de gran proporción. También es importante que se tomen medidas de mitigación como el dragado del Río en las zonas críticas de inundación para evitar futuras catástrofes. 
Por último, cabe anotar que las imágenes con las cuales se trabajó provienen de una sola fuente de información, en este caso el IGAC, razón por la cual el proyecto se vio restringido a utilizar imágenes de diferente tipo de sensor (Activo y pasivo), dado que para las fechas posteriores a la ocurrencia de la inundación en la zona específica, el único insumo disponible fue la imagen de radar

\section{AGRADECIMIENTOS}

Los autores expresan sus agradecimientos a la Universidad Militar Nueva Granada y en especial al Programa de Especialización en Geomática por su apoyo en la elaboración del presente proyecto.

\section{REFERENCIAS}

[1] Morelli Tucci C. (2007). Gestión de Inundaciones Urbanas. Porto Alegre.

[2] Hudson P y Colditz R. (2003). Flood delineation in a large and complex alluvial valley, lower Pánuco basin, México. En: Journal of Hydrology, 280, pp. 229-245.

[3] Soldano A., Giraut M y Goniadzki D. (2007). Mapa de susceptibilidad urbana ante inundaciones caso: Ciudad de Goya, provincia de Corrientes. En: XII congreso de la asociación española de teledetección.

[4] Smitth, Laurence C. (1997). Satellite remote sensing of river inundation area, stage, and discharge: a review. Hydrological Processes, vol. 11, 1427-1439.

[5] Jacobson, C. R. (2011). Identification and quantification of the hydrological impacts of imperviousness in urban catchments: a review. Journal of Environmental Management, 92, 1438-1448.

[6] Montesinos A, Salomón. Desarrollo metodológico para la evaluación del riesgo de erosión hídrica en el área mediterránea utilizando técnicas de teledetección y GIS. Tesis Doctoral. Universidad Complutense de Madrid, Facultad de Ciencias Geológicas.

[7] Análisis de riesgo por inundaciones y deslizamientos de tierra en la microcuenca del arenal de Montserrat. (2003). Servicio Nacional de Estudios Territoriales. San Salvador, El salvador.

[8] Soldano A. (2008). Teledetección aplicada a la reducción del riesgo por inundaciones. Comisión Nacional de Actividades Espaciales y Departamento de Desarrollo Sostenible de la Secretaría General de la Organización de los Estados Americanos.

[9] Cárdenas P, Aldo. Aplicación de sistemas de información geográfica para el modelamiento de zonas con riesgo de inundación. Caso estudio Río Lurin.

[10] Rebolledo W., Vergara W., Guevara V., Yépez S., Reyes A y Arismendi J. Sistema de información geográfica para la gestión de riesgo por deslizamiento de tierras e inundación del eje Araira - El Salmerón 
del municipio Zamora del estado Miranda. Fundación Instituto de Ingeniería, centro de procesamiento digital de imágenes.

[11] Goyeneche Herrera J. (2012). Plan de Desarrollo Municipal 2012-2015. Municipio de Paz de Río. Boyacá.

[12] Fernández, Felipe. (2000). Introducción a la Fotointerpretación. Editorial Ariel Geografía. España.
[13] Municipio Paz de Río. Consultada en marzo del 2013. En: http://pazderio-boyaca. gov.co/nuestromunicipio.shtml?apc=$m l x x-1-\& m=f$.

[14] Esquema de Ordenamiento Territorial (EOT) del Municipio de Paz de Río (Boyacá). (2007).

[15] Muñoz Montoya C. (1999). Modelos Digitales de Elevación, Aplicaciones desde Surfer. Cali. Universidad del Valle. 